\title{
Influence of major fault zones on 3D ground deformations caused by open pit block cave interactions
}

\author{
J. Severin Geological Engineering, The University of British Columbia, Canada \\ E. Eberhardt Geological Engineering, The University of British Columbia, Canada
}

K.S. Woo Geological Engineering, The University of British Columbia, Canada

\begin{abstract}
Surface mining operations are increasingly transitioning to underground mass mining operations like block caving to extend the life of the mine. The presence of the open pit above the developing block cave will lead to complex stress-strain interactions, pit slope movements and ground deformations that may extend beyond the periphery of the pit, potentially having an adverse effect on mine infrastructure and operations within the zone of disturbance. These can be further complicated by major fault zones that crosscut the mine property. Experiences at the Palabora Copper Mine in South Africa provide one such example of a transition to block cave mining where the interactions that developed between the underground workings and overlying steep rock slopes evolved into a massive $800 \mathrm{~m}$ high pit slope failure. To properly assess the rock mass response to these interactions for the management of pit slope stability, surface subsidence and setback distances for mine infrastructure outside the pit rim, as well as for planning future underground development, understanding the controlling influence of geological structures on the ground response is crucial. Results are presented here from a series of $3 D$ continuum and discontinuum numerical models that investigate the interactions between the open pit, block cave mine and large scale geological features present at Palabora. These results are compared to a detailed review of pit slope monitoring data to help provide understanding of the complex slope displacement patterns recorded and apparent pit slope kinematics.
\end{abstract}

\section{Introduction}

As near surface resources become depleted, open pit mining operations approaching the end of their mine life are considering the transition to underground mass mining. This transition allows the mine to recover deeper reaches of the orebody. The complex mine designs this involves and the variable nature of geologic and geomechanical structures (faults, pervasive jointing, etc.), creates the potential for complex pit slope movements and surface subsidence that may adversely affect mine infrastructure causing both safety and economic concerns.

Large-scale geological structures can play a controlling role in the kinematics and stability of pit slopes (Stacey and Swart, 2001). With the added consideration of the large-strain interactions induced through the underground mass mining operations, the resulting pit slope deformation patterns become progressively more difficult to interpret with respect to how they will continue to evolve. This leads to uncertainty in assessing the stability of the slopes, setting early warning alarm thresholds and/or determining setback distances for mine infrastructure located near the crest of the pit slope. A number of cases exist where sudden collapses of cave backs, crown pillars, etc., have occurred due to unknown geological structures or unexpected rock mass behaviour, including the hangingwall wedge failure at the Kidd Creek mine in Canada that propagated from $610 \mathrm{~m}$ depth to surface (Board et al., 2000), the $800 \mathrm{~m}$ high pit wall failure at Palabora in South Africa (Brummer et al., 2006), or the fatal air blast caused by the sudden collapse of the cave at the Northparkes Mine in Australia (Hebblewhite, 2003).

Accordingly, the explicit representation of key geological features in a 3D numerical model may be required to properly reproduce the pit wall kinematics and stress-strain interactions that may develop in response to block cave mining below the pit. This paper presents the preliminary results of a detailed study integrating mine site geology and monitoring data with advanced 3D numerical modelling to investigate the effects that large scale fault systems can have on caving induced subsidence and pit slope deformations. 


\section{$2 \quad$ Numerical modelling of geological structures and subsidence}

Numerical modelling is a powerful tool used to break down complex problems into their constituent parts and analyse cause and effect relationships, and their evolution, under changing model conditions. Several methods (finite difference, finite element, distinct element, etc.) have been employed in various block caving studies, modelling caving potential and fragmentation, cave propagation and surface subsidence, and interactions between a block cave and overlying open pit. One common element to all numerical models is the difficulty of including representative geological heterogeneity. The importance of doing so was demonstrated by Vyazmensky et al. (2009), who showed that the orientation of both macro and meso-scale geological structures played a controlling factor in the 2D modelling of fragmentation, block cave propagation and caving induced subsidence using a hybrid finite/discrete element brittle fracture code (Rockfield Software's ELFEN). Figure 1 shows one of the results from this study in which the influence of joint orientation on cave propagation and surface subsidence asymmetry is modelled. Vyazmensky et al. (2009) study also looked at fault location for a dipping fault at different offset distances from the centre of the undercut. The results suggested that faults intersecting the cave, or in close vicinity, may create favourable conditions for caving to extend into the hangingwall block of the fault, thereby extending the area of subsidence as well.

Beck et al. (2006) also looked at the influence of geological structures in the context of an interacting cave and pit using the 3D finite element continuum program ABAQUS (see also Arndt et al., 2007). Their analyses examined the dissipated plastic energy inherent in the inelastic material model. Geological structures were inserted into the model as zones of weakness, the results of which showed that the geologic structures had a direct correlation to areas of increased plastic strain within the model, i.e. along these features (Figure 2). It should be noted though that although the localised stress-strain response of these zones of weakness can be effectively modelled using a finite element approach, the continuum representation of the problem domain does limit the model's ability to simulate certain kinematic aspects of rock mass failure related to the presence of discontinuities and faults.

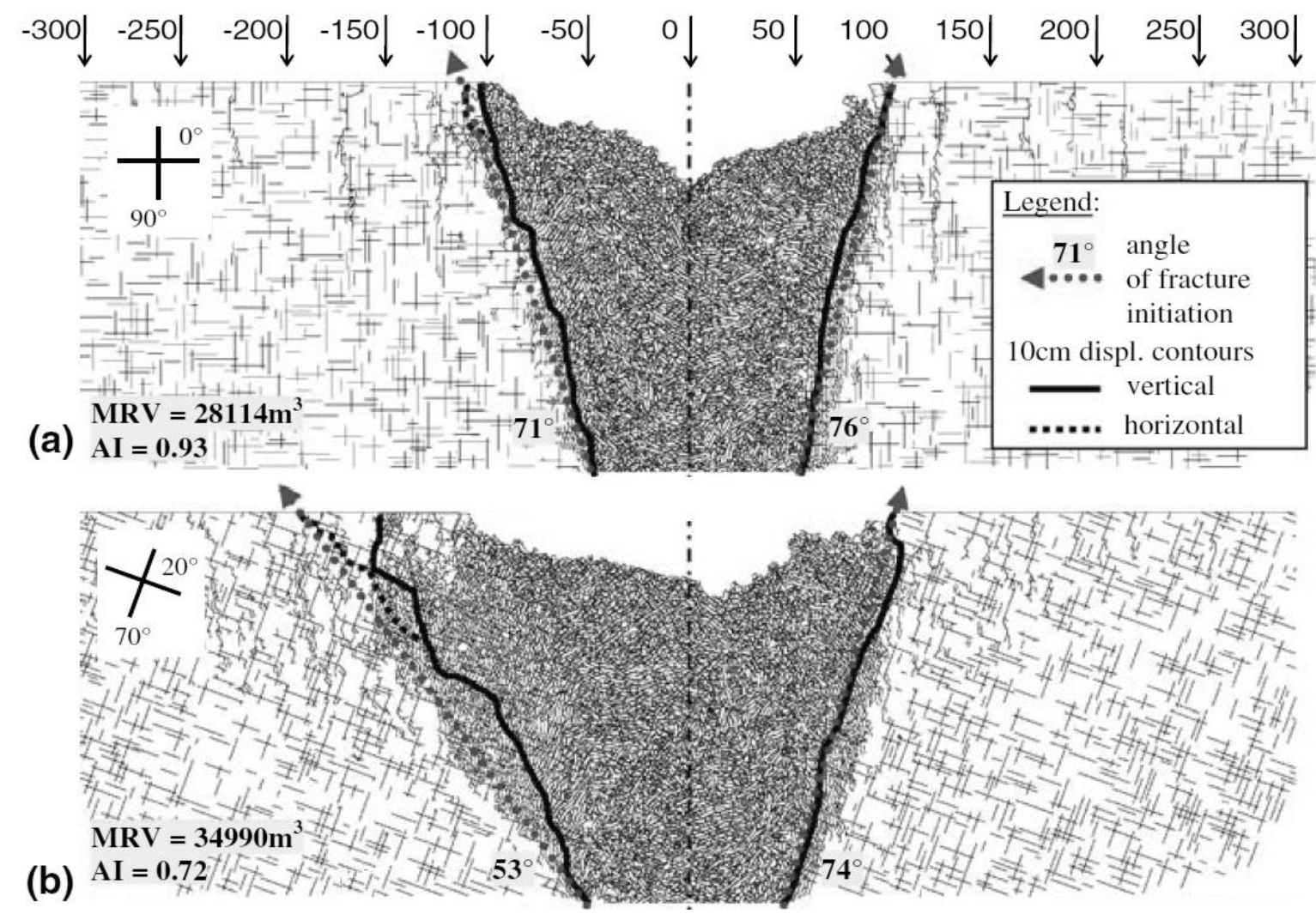

Figure 1 Brittle fracture modelling of influence of joint pattern on caving (Vyazmensky et al., 2009) 


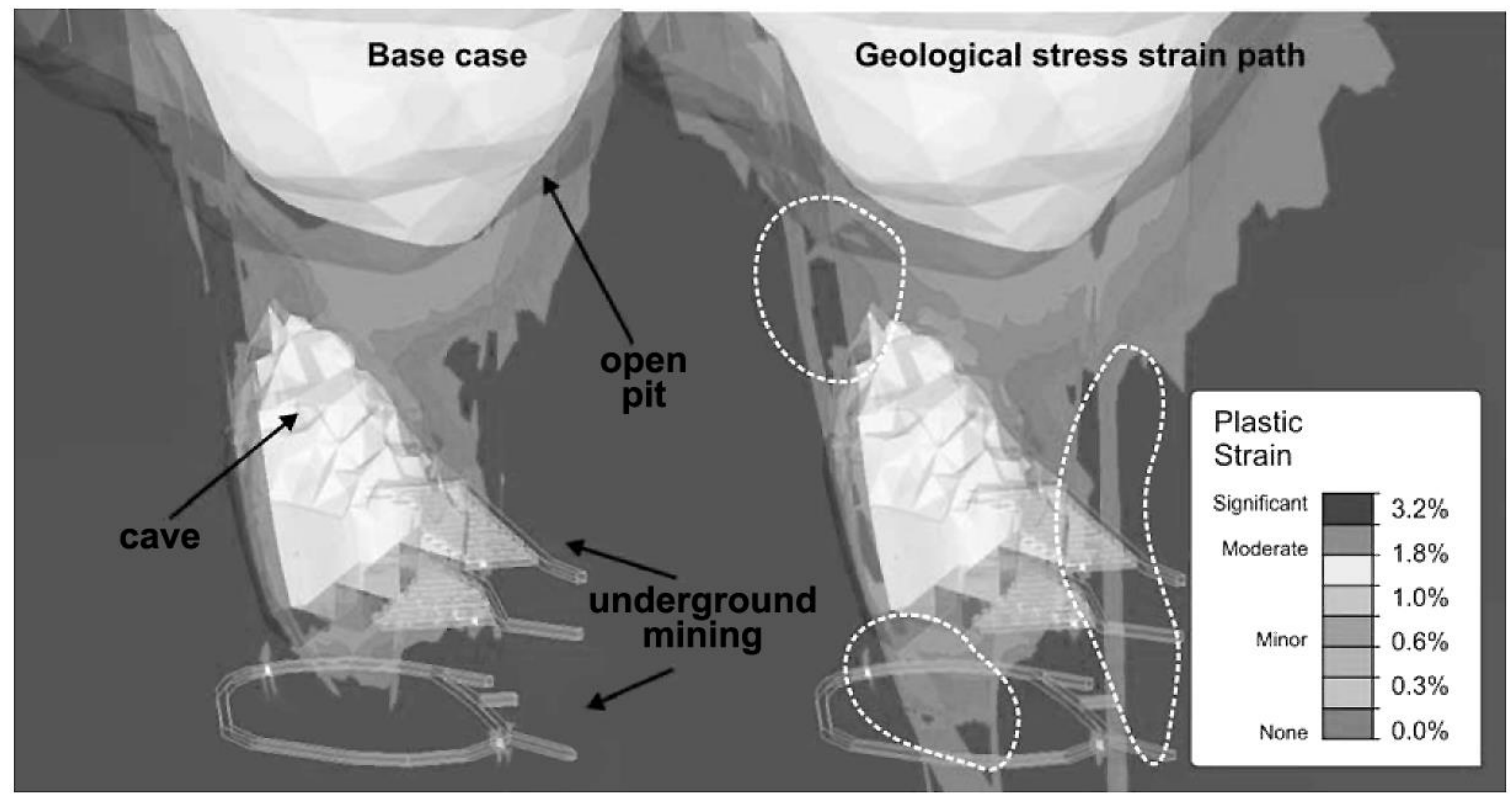

Figure 2 3D finite element modelling of plastic strains caused by interaction between open pit and block cave; zones of weakness representing faults circled by dashed lines (Arndt et al., 2007)

Brummer et al. (2006) demonstrated the importance of geological structures with respect to kinematic controls using the discontinuum based 3D distinct element code 3DEC (Itasca, 2003). The distinct element method allows for the explicit inclusion of geological structures and rock mass heterogeneity within the model, representing the problem domain as an assemblage of discrete blocks. The discontinuities are treated as boundary conditions between blocks where large displacements along discontinuities may develop through opening or shearing. Such models are strongly dependant on the contact properties between blocks, which govern their interactions. By using this technique, Brummer et al. (2006) were able to obtain a basic understanding of the interaction between the open pit and underground mass mining operation at Palabora as influenced by the representation of the geology captured in the model.

\section{Study site - Palabora Copper Mine}

\subsection{Mine characteristics and production}

The Palabora Copper Mine is located approximately $500 \mathrm{~km}$ northeast of Johannesburg, South Africa. Mining commenced in 1964 as an open pit operation, producing a pit measuring approximately $800 \mathrm{~m}$ in depth and $1,650 \mathrm{~m}$ across by the end of the pit life in 2002. Inter ramp angles ranged from $37^{\circ}$ in the upper weathered rock to $58^{\circ}$ in the competent lithologies at the base of the pit (Moss et al., 2006). The mine successfully transitioned into a block caving operation with underground production commencing in April 2001 and increasing gradually until full production was achieved in May 2005. Important caving milestones in relation to its effect on the surface environment include:

- December 2002, the crown pillar was noted to be de-stressed (based on microseismic data)

- March 2003, hydraulic conductivity was observed between the pit bottom and underground cave

- December 2003 (estimated), cave break through into the pit.

The current production level of the underground mine is located approximately 1,200 $\mathrm{m}$ below surface and $400 \mathrm{~m}$ below the final pit bottom (Figure 3 ). The production level currently consists of 20 crosscuts resulting in a footprint $650 \mathrm{~m}$ long by $250 \mathrm{~m}$ wide. 

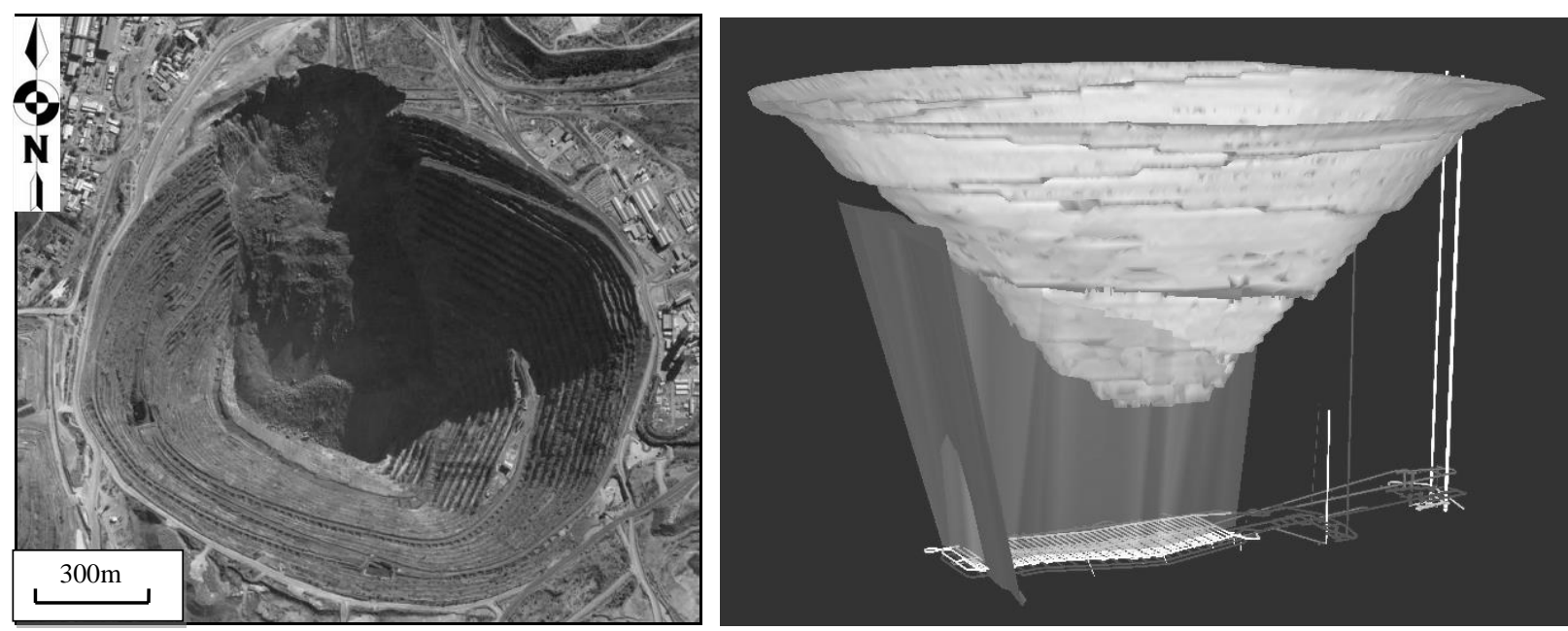

Figure 3 Quickbird image of Palabora Mine after 2005 pit failure (left), and 3D spatial relationship between the underground operations, open pit and Mica fault (right)

\subsection{Mine site geology}

The orebody at Palabora involves a subvertical volcanic pipe emplaced within pyroxenite. A primary intrusion of micaceous pyroxenite was subsequently intruded by foskerite and banded carbonatite with late stage fracturing and intrusion resulting in the emplacement of a transgressive carbonatite body. Late stage dolerite dykes with steeply dipping northeast trends are also present as are a number of northwest and northeast trending faults. Figure 4 shows the four main faults found within the pit. Amongst these, the Mica fault is described as being an approximately $60 \mathrm{~m}$ wide sheared rock mass composed of mostly large rock blocks, fault breccia and fault gouge.

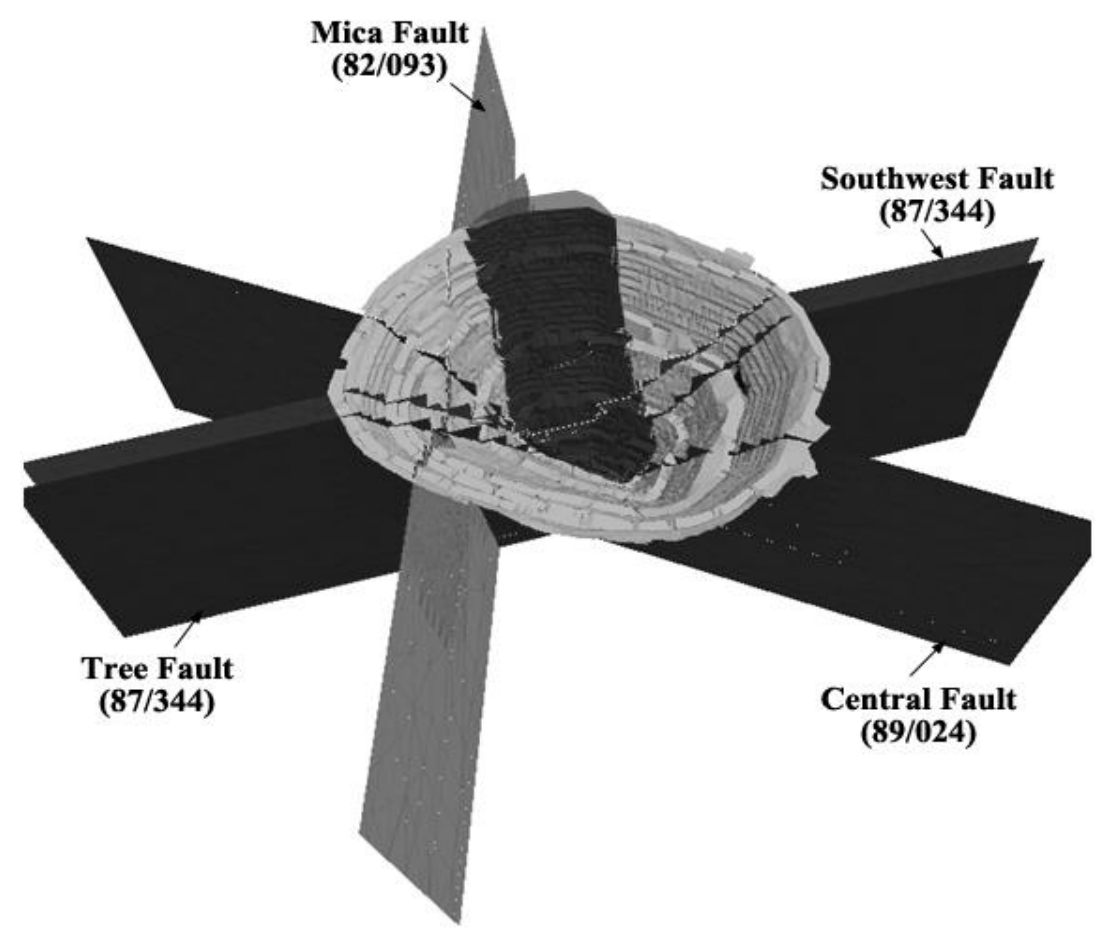

Figure 4 3D geological model of Palabora open pit showing major faults. North is towards the top

\subsection{Pit movement and failure}

Shortly after breakthrough of the cave into the floor of the mined out open pit, the northwest wall at Palabora experienced a multi-bench failure in 2004. The location of the failure is shown in Figure 3 (left) and outlined 
in dark within pit in Figure 4. The failure mechanism likely involved a combination of slip along existing structures and brittle failure of the rock mass in response to the undermining of the slope toe by the developing block cave. Prior to the failure, a series of complex slope movements occurred in 2003 shortly after the crown pillar became destressed. Movement of all pit walls increased substantially upon cave breakthrough into the bottom of the pit with the largest deformations observed in the North wall. Tension cracks were first observed inside of the pit in April 2004, and by June 2004 the displacement boundaries were well defined. Failure of the northwest wall was gradual and continued to develop slowly over a period of 18 months. Brummer et al. (2006) observed that within the main zone of movement on the northwest wall, most of the visible deterioration of the rock mass was along the western and eastern boundaries and that the central portion of the slide mass appeared to remain relatively intact. However, by 2008, the central block of the failed mass also appeared to be heavily deteriorated.

\section{$4 \quad$ Interpretation of geodetic pit slope monitoring data}

Monitoring data represents an important constraint for complex 3D numerical models. However, the interpretation of monitoring data is far from straight forward and can be affected by the same issues of rock mass complexity, heterogeneity and uncertainty that affects the numerical models the data are meant to constrain. Accordingly, a detailed review of the geodetic monitoring data collected at Palabora between 1984 and 2004 was undertaken in order to gain an understanding of the kinematic state and key geological controls within the pit (Severin et al., 2009). The geodetic review primarily considered the effect of large-scale structures such as faults and shear zones and their possible effect on observed displacement. Displacement rates, cumulative displacement, and direction of displacement with respect to the major faults (Figure 4) were analysed in order to understand the pattern of displacement in and around the pit. Note that only the reviews of the North and West walls are presented here, for the time period during the commencement of block cave mining until the failure of the northwest wall.

During pit deepening, prior to caving, total displacement in the West and North walls indicate that the rates were fairly consistent throughout the pit except for an area in the northwest section of the pit bounded by the Mica and Central faults. This area experienced slightly higher displacements. Review of the horizontal and vertical incremental displacement values show that the vertical component of displacement was dominant in both up and down directions; this suggests that both strain relief (rebound) and downward relaxation of the slopes towards the pit were active components in response to mining. In general, the displacement rates can be seen to increase with pit deepening, with the displacement vectors prior to block caving pointing towards the bottom of the West wall and middle of the pit. The shaded circle in Figure 5(a) represents the average direction in which the West wall displacement vectors point. Prisms located in close proximity to the Mica and Southwest faults, however, do tend to displace toward these structural features, possibly due to the compression of broken rock within the brecciated fault zones. Minor movements along the Mica Fault in a strike-slip direction during pit deepening can also be observed in the data.

Following initiation of the caving operations in April 2001 and progressing up to the 2004 pit wall failure, the pattern of displacements observed in the geodetic prisms in the West and North walls change noticeably. The geodetic data indicates that the movement of the West wall deviated from the centre of the pit to point towards a location beneath the northwest wall (Figure 5(b)). This location roughly corresponds to the location of the eventual failure, which is superimposed on Figure 5(b). Microseismic data collected at Palabora (Glazer, 2003) supports the displacement data interpretation that the caving front migrated from beneath the centre of the pit to beneath the North wall. The monitoring data also suggests that some strike-slip movement may have occurred in response to the growing caving front. A majority of prisms located on the west side of the Mica fault (footwall) underwent a sharp distinct movement to the southwest during January to February 2002, whereas those prisms located on the east side of the Mica fault (hangingwall) did not.

The temporal changes in the West wall resolved from the analysis of the geodetic data reveal several interactions that are important to understanding the 3D kinematics of the slope in response to block caving. For example, the West wall prisms began to move toward the North wall in stages. Prisms located east of the Mica fault (both on the northwest and southwest walls) show consistent movement toward the failure zone as early as January 2003, whereas those prisms to the west of the Mica fault did not begin to move in this direction until June 2003. This delay suggests that the Mica fault may have partially shielded the upper West 
wall from movement during this period of cave propagation. The Mica fault consists of a zone of brecciated rock, which would allow most of the extensional strains caused by the advancing cave to be diffused through dislocation and opening rather than transferred across to the west side of the fault.

Prior to the northwest wall failure, a small movement was observed in October 2003 in which only the area between the Mica and Central faults was involved. The movement was to the north, along strike of the Mica fault, into the projected area where the cave front was believed to be migrating. Displacement rates prior to this movement were steady at levels only slightly higher than those observed prior to the initiation of caving; after breakthrough vertical displacement rates increased (three to five times) for the bounded block relative to the surrounding areas of the wall. This artefact is interpreted as the pit wall subsiding towards the cave front as it migrated towards and underneath the toe of the northwest wall. Contouring of the vertical displacements at the time of cave breakthrough is shown in Figure 6. The geodetic data suggests that at the time of cave breakthrough, the area of the pit wall that would eventually fail had undergone significantly more subsidence than the surrounding areas. It should be noted that the lower limits of the contours in this figure are cutoff at the foot of the slope due to the absence of geodetic data for the bottom benches of the pit; the bottom of the pit would have experienced the highest vertical displacements in response to the cave breakthrough. Furthermore, notwithstanding the absence of geodetic data for the pit bottom, the data also suggests that the caving induced subsidence within the pit was largely contained within an area on the North wall bounded by the Central and Southwest faults (Figure 6).

In summary, the following working hypotheses were developed based on the review and analysis of the Palabora geodetic data: i) the caving front acted as the dominant control for the pit slope movements observed, but that the major fault zones transecting the pit also had a significant influence; ii) the subvertical nature of the geologic structures tend to promote vertical movements, while damping those that are horizontal and extensional, and having little to no affect on those that are horizontal and in compression; iii) the Mica Fault shielded the West wall from induced strains during breakthrough of the cave and failure of the northwest wall, iv) the location of the cave front along with the vertical nature of the geologic structures interacted to promote subsidence of the northwest wall with a feedback that promoted migration of the cave back towards the northwest wall; and v) the cave back does not appear to migrate up and along one of the major faults, but rather along the dominant joint set in the North wall.
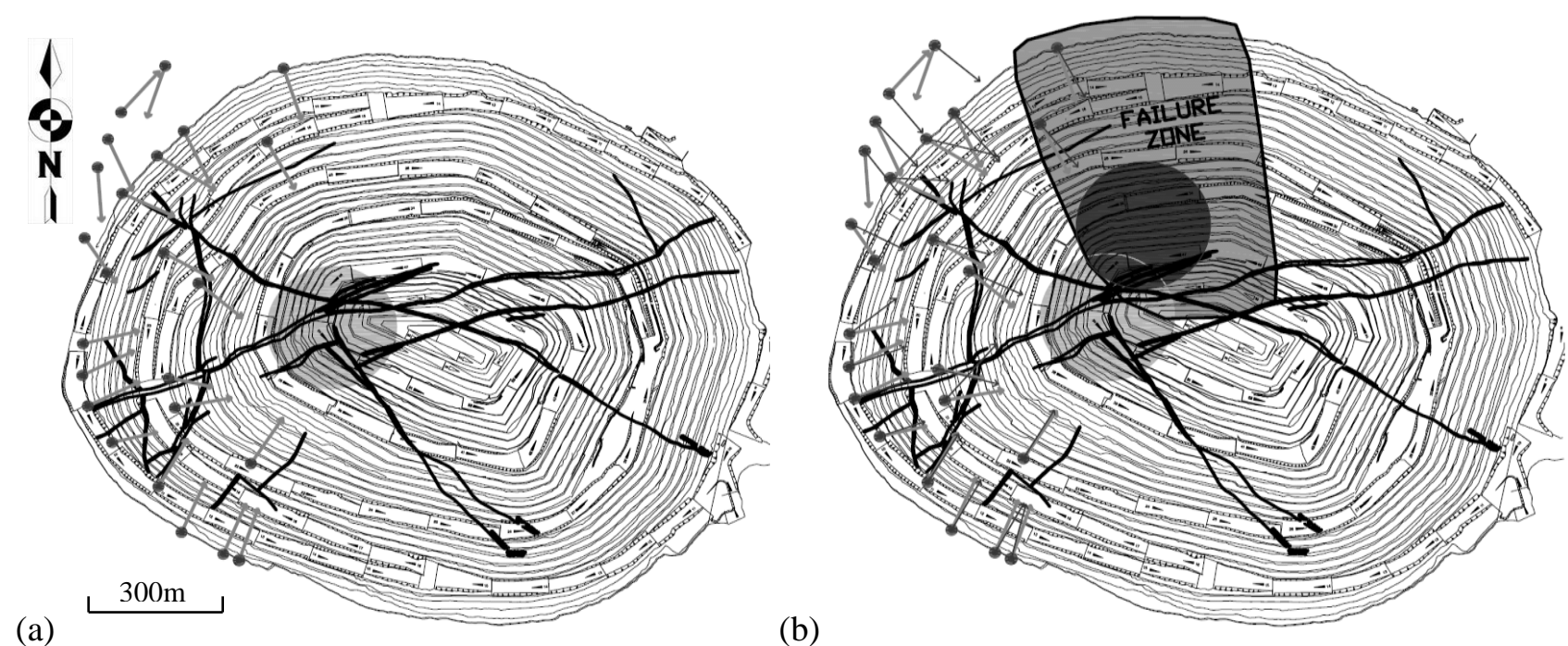

(b)

Figure 5 (a) Pre-cave displacement vectors highlighting average direction of movement; (b) change in direction of displacement vectors from before (lower circle) and after (upper circle) commencement of caving. Shaded circles indicate average direction of movement for corresponding set of vectors 


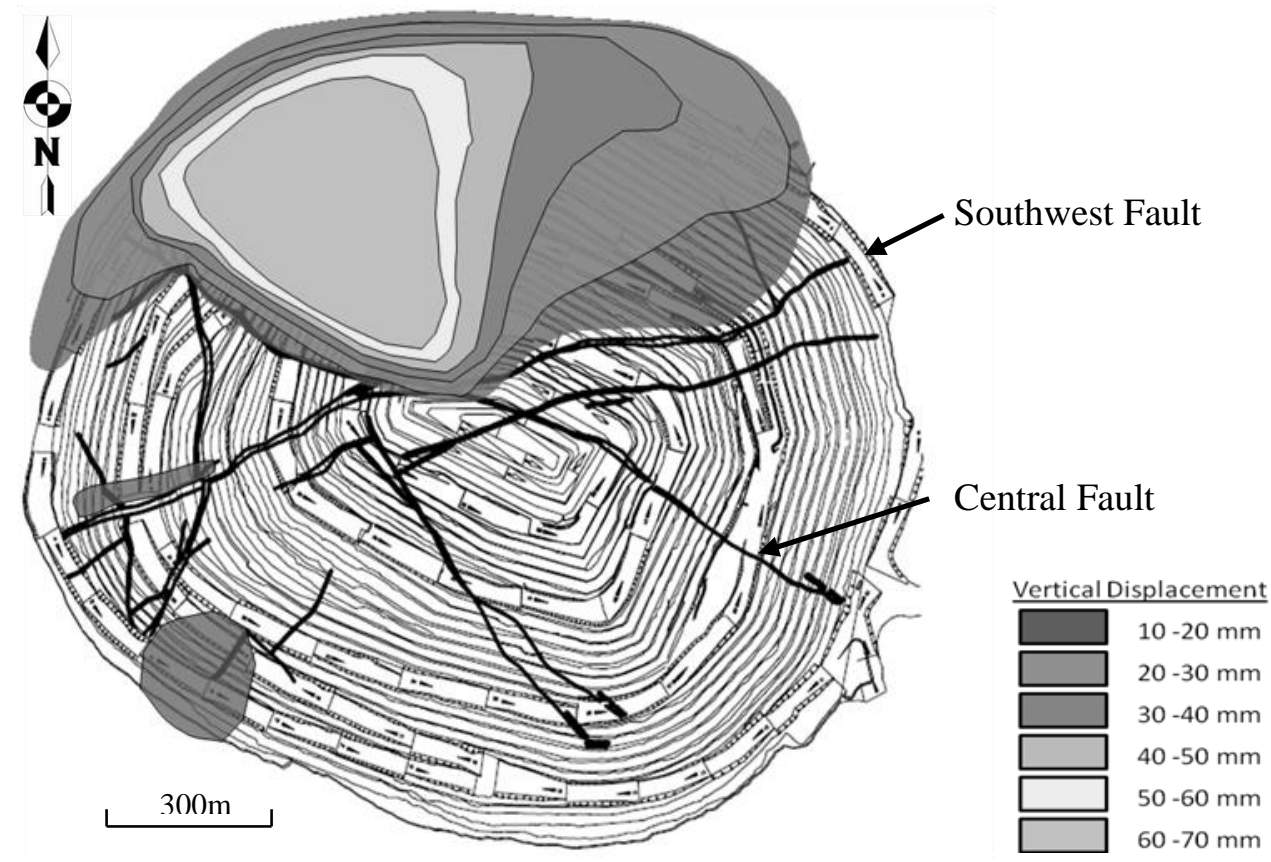

Figure 6 Vertical displacement pattern based on geodetic monitoring before and up to cave breakthrough

\section{$5 \quad$ Numerical analysis of subsidence at Palabora}

\subsection{Model geometry}

In their work on the Cadia Hill open pit mine, Sainsbury et al. (2007) demonstrated the effectiveness of 3DEC (Itasca, 2003) in accurately modelling complex 3D slope failure mechanisms that require both rock mass yielding and slip along geological structures. Numerical modelling of Palabora was therefore carried out using 3DEC to simulate the subsidence and deformation observed during block caving leading up to breakthrough of the cave into the pit bottom.

Development of the Palabora model was based on typical mine data. The mine geometry was created within the 3D CAD software Rhino3D using the pit and underground mine plans. Within the CAD model, the shape of open pit was simplified to allow the removal of all non-conforming blocks within 3DEC. The shape of the cave was projected from the undercut assuming a break angle of $85^{\circ}$, with constraints imposed by measuring the outline of the cave breakthrough into the pit bottom from satellite Quickbird images, combined with projections at depth based on production tonnage and microseismic data. Cave propagation between the undercut and surface breakthrough was then divided into three stages. This approach to modelling the influence of the cave was selected over alternative approaches, such as that by Sainsbury et al. (2008) who used FLAC3D and a ubiquitous joint rock mass (UJRM) technique to model cave propagation directly. Figure 7 shows the model and assumed cave geometry divided into the three stages of cave development over time.

Lithological boundaries were simplified to represent the host rock, a weathered pyroxenite, and the orebody, a carbonatite, as a single material. This was done in order to focus the model results on the influence of the major faults; it should be also noted that the range of properties derived for the two rock types overlap. The major faults, as identified in Figure 4, were explicitly represented in the model as discrete surfaces. These were simplified as planar structures (Figure 7). The CAD model was then imported into 3DEC using the 3D meshing program Kubrix to generate the geometrically complex problem domain using convex blocks. 

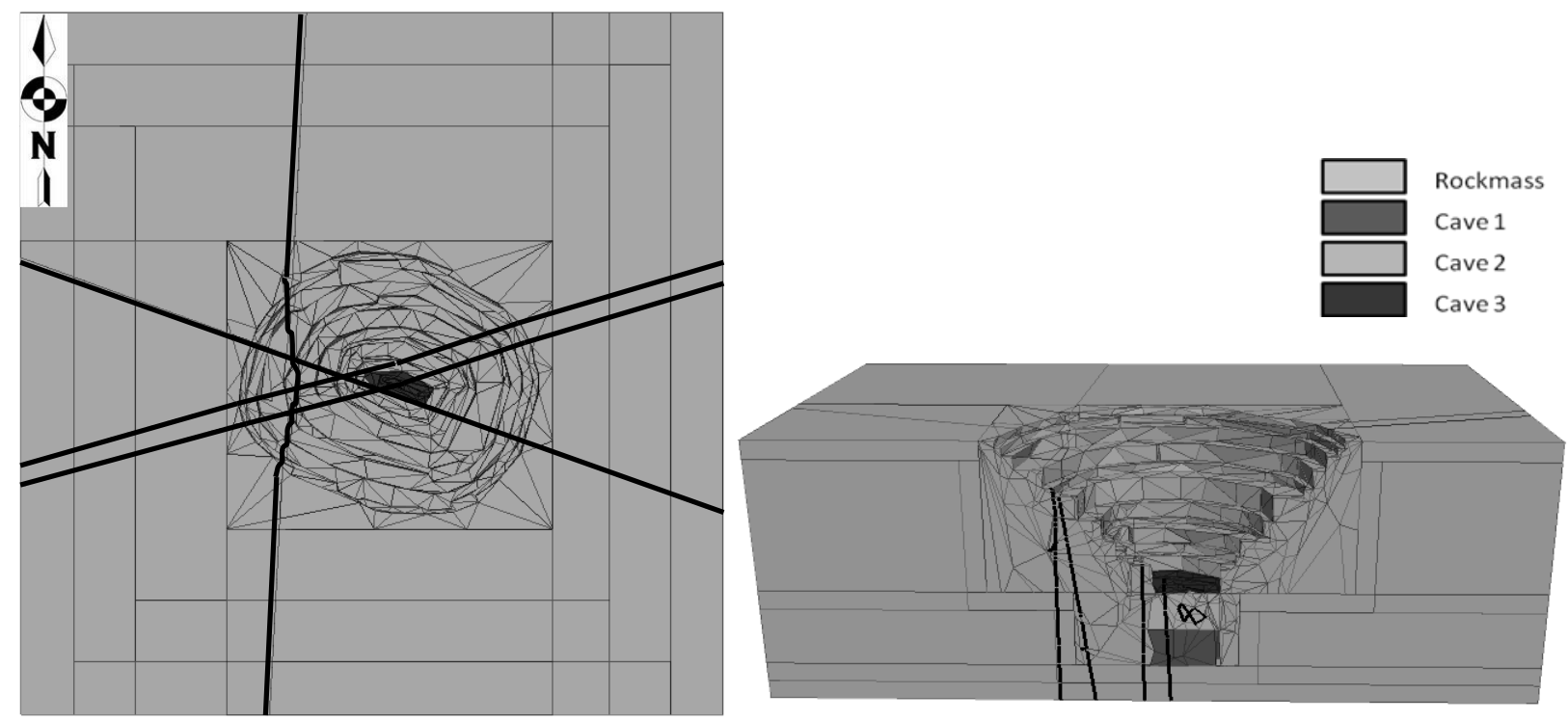

Figure 7 Plan and section views of the pit, fault and cave geometries modelled in 3DEC

\subsection{Rock mass properties}

Modelling to date has focussed on using a Mohr-Coulomb elasto-plastic constitutive model to represent the individual blocks in the model, treating them as an equivalent continuum rock mass that incorporates the strength reducing effect of the smaller scale discontinuities not explicitly included in the models. Future models will explore other constitutive models including strain softening and UJRM in order to better represent post-peak strength degradation of the yielded rock. The faults were assigned a Coulomb slip constitutive model. Estimates of the rock mass and fault properties were based on estimates derived from laboratory testing and field mapping data (i.e. RMR), as reported by Piteau Associates (2000, 2005). Tables 1 and 2 present the input properties used. Groundwater conditions within the pit were assumed to be dry in accordance with the semi-arid climate of the region and dewatering work carried out.

Table 1 Rock mass and caved rock properties

\begin{tabular}{lllllll}
\hline Model Units & $\begin{array}{l}\text { Density } \\
\left(\mathbf{k g} / \mathbf{m}^{\mathbf{3}}\right)\end{array}$ & $\begin{array}{l}\text { Cohesion } \\
(\mathbf{M P a})\end{array}$ & $\begin{array}{l}\text { Friction } \\
\text { Angle }(\mathbf{d e g})\end{array}$ & $\begin{array}{l}\text { Bulk Modulus } \\
(\mathbf{G P a})\end{array}$ & $\begin{array}{l}\text { Shear Modulus } \\
(\mathbf{G P a})\end{array}$ & $\begin{array}{l}\text { Tension } \\
(\mathbf{k P a})\end{array}$ \\
\hline Rock mass & 3,100 & 2.9 & 36 & 9.4 & 5.7 & 100 \\
Caved rock & 2,300 & 0 & 30 & 0.42 & 0.19 & 0 \\
\hline
\end{tabular}

Table 2 Shear strength properties for major faults

\begin{tabular}{llllllll}
\hline Structure & $\begin{array}{l}\text { Dip } \\
(\mathbf{d e g})\end{array}$ & $\begin{array}{l}\text { Dip Dir. } \\
(\mathbf{d e g})\end{array}$ & $\begin{array}{l}\text { Cohesion } \\
(\mathbf{k P a})\end{array}$ & $\begin{array}{l}\text { Friction } \\
\text { Angle } \\
(\mathbf{d e g})\end{array}$ & $\begin{array}{l}\text { Normal } \\
\text { Stiffness } \\
(\mathbf{G P a} / \mathbf{m})\end{array}$ & $\begin{array}{l}\text { Shear } \\
\text { Stiffness } \\
(\mathbf{G P a} / \mathbf{m})\end{array}$ & $\begin{array}{l}\text { Tension } \\
(\mathbf{k P a})\end{array}$ \\
\hline Mica fault & 82 & 093 & 0 & 10 & 8.0 & 0.4 & 0 \\
Southwest fault & 87 & 344 & 5 & 25 & 8.0 & 8.0 & 0 \\
Central fault & 89 & 024 & 0 & 10 & 8.0 & 8.0 & 0 \\
Tree fault & 87 & 344 & 5 & 25 & 8.0 & 8.0 & 0 \\
\hline
\end{tabular}

\section{$6 \quad$ Modelling results}

For comparative purposes, the discontinuum based 3DEC models were first compared to those modelled in FLAC3D as a continuum. The same CAD model was used minus the explicit representation of the faults for 
the FLAC3D models. Both sets of models were solved in four stages: i) initial equilibrium, ii) caving to $50 \%$ of full height, iii) caving up to the pit bottom, and iv) caving into the pit bottom and full breakthrough. Modelling of each caving stage was carried out by changing the material properties of the rock mass within the caved interval to those for broken rock (i.e. caved ore), and by resetting the stresses within the cave to those representing the self-weight of the caved material from the locked in in situ stresses initialised.

\subsection{Continuum response}

Figure 8 illustrates the subsidence pattern modelled by FLAC3D for the previously described set of input parameters and model constraints. The modelled vertical displacements at cave breakthrough are depicted in plan and cross section. The stress-strain interactions between the cave and open pit results in yielding and increased displacements in the North wall of the pit, roughly coinciding with the concentration of vertical displacements observed in the geodetic data (Figure 6) and the eventual pit wall slope failure. These results suggest that the topography of the open pit and the location of the undercut and cave combine to direct and concentrate the stresses and deformation to the north of the pit.

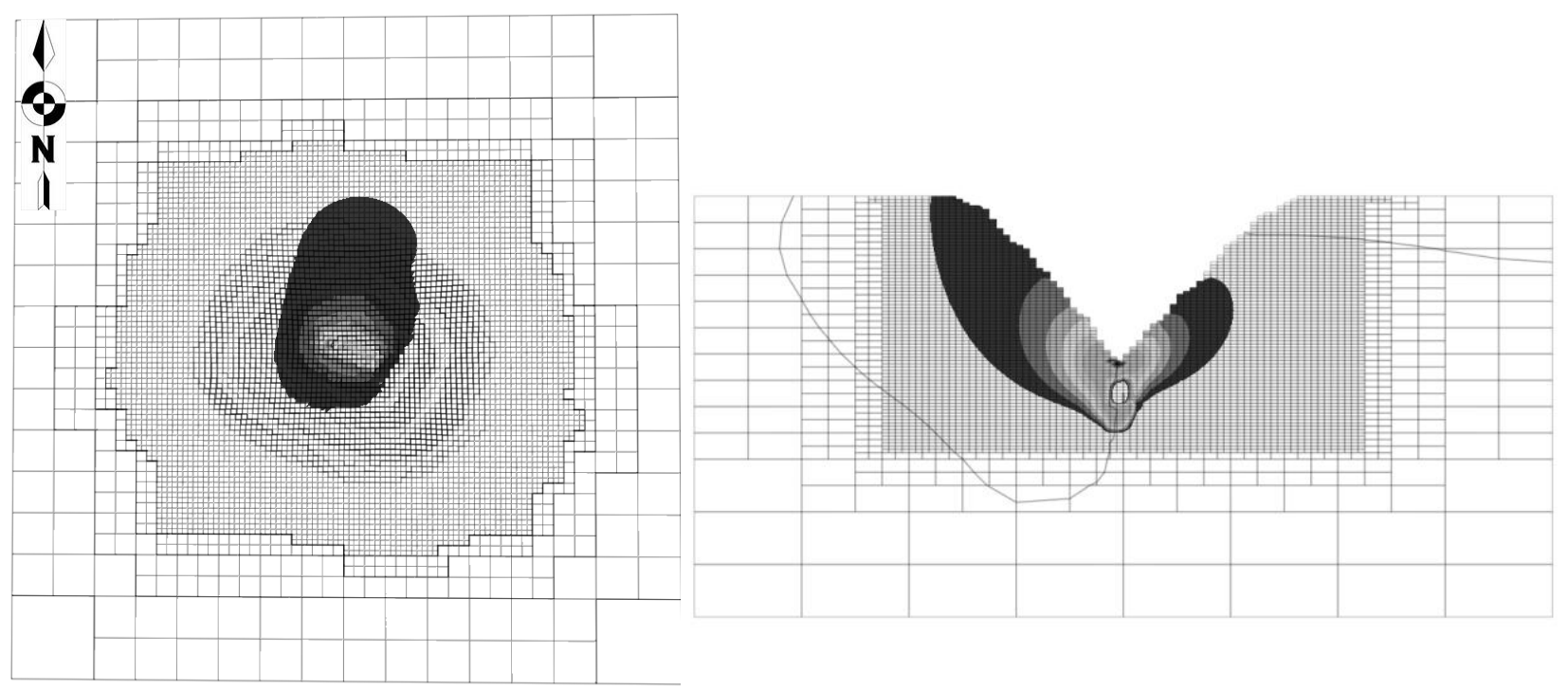

Figure 8 Modelled FLAC3D (continuum-based) vertical displacements upon cave breakthrough, in plan view (north towards top) and section through the eventual failure location. Contours show displacements greater than $1 \mathrm{~cm}$

\subsection{Discontinuum response}

Although the FLAC3D continuum model reproduces the general location of where the prefailure pit slope displacements concentrate, the pattern does not exactly match the geodetic data or outline of the actual failure location (see Figures 6 and 3, respectively). Figure 9 illustrates the surface subsidence pattern in plan and cross-section at the time of cave breakthrough obtained using 3DEC. The inclusion of the major faults results in a better fit to the subsidence pattern derived in Figure 6. Inspection shows that the faults accommodate movement, which leads to concentrated stresses and discontinuous displacements across the pit walls. 


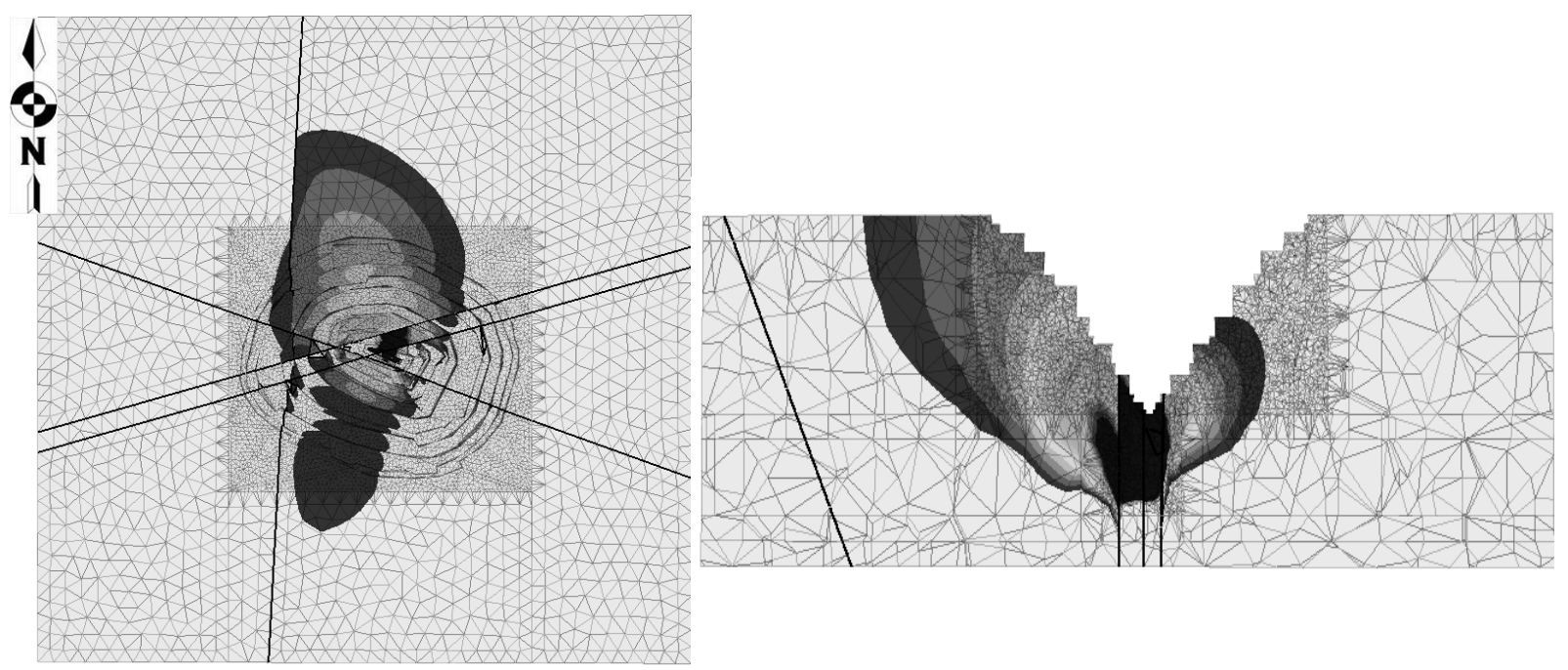

Figure 9 Modelled 3DEC (discontinuum-based) vertical displacements upon cave breakthrough, in plan view (North towards top) and section through the eventual failure location. Contours show displacements greater than $1 \mathrm{~cm}$

Comparisons between the two models show that the concentration of stresses created by the inclusion of the faults leads to increased subsidence across the North wall, directed towards the location of the eventual 2004 failure. In plain view (Figure 9), a decrease in the amount of displacement that develops to the west of the Mica Fault is observed as the cave does not extend beyond the Mica Fault at that location. Also, the displacements in the South wall are better represented. Along the cross section through the centre of the eventual failure, a higher concentration of strain and displacement develops is illustrated in the 3DEC model away from the cave even though there are no faults directly aligned with the section. As such, the overall shape of displacement profile does not change between the 3DEC and FLAC3D models. However, along sections in the 3DEC model where a fault does cross, for example the east-west section of the model, the shape of displacement contours is dramatically altered. Figure 10 directly compares the shape of the subsidence patterns without and with the faults. Here the inclusion of the Mica fault shields the region behind the fault from the extensional strains that develop as the rock moves towards the cave. This corresponds well to conclusions derived from the geodetic data that the Mica fault served to partially shield the upper West wall from the caving induced strain and displacements upon cave breakthrough (Severin et al., 2009).

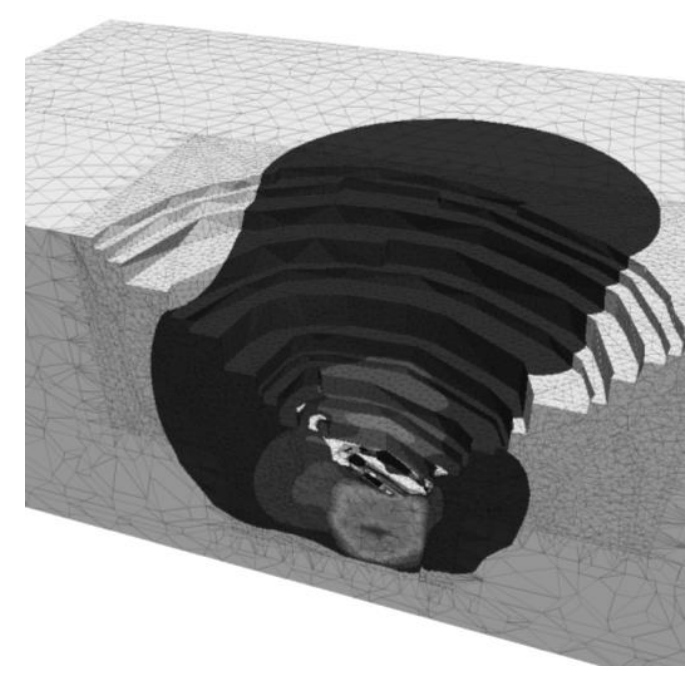

(a) without faults

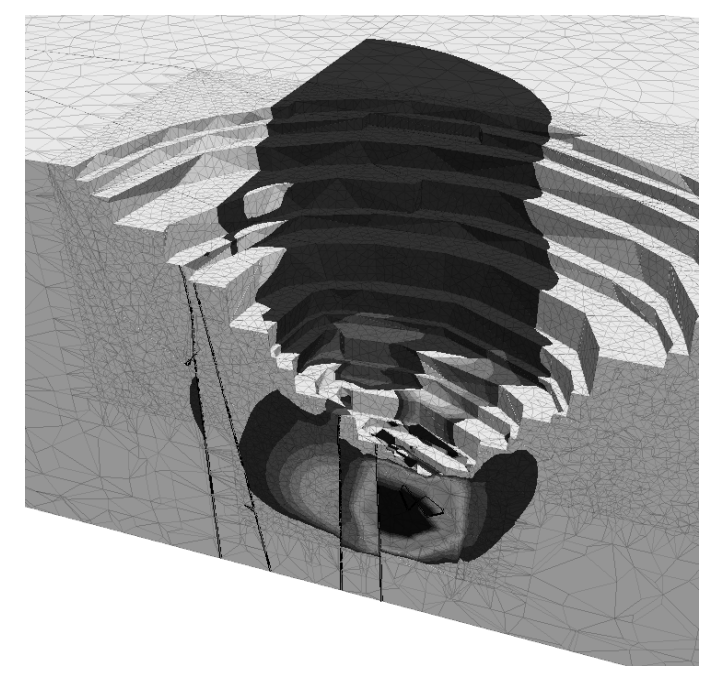

(b) with faults

Figure 10 East-west isometric view of subsidence corresponding with cave breakthrough, for models (a) without faults; (b) with faults. Contours show displacements greater than $1 \mathrm{~cm}$ 
Figure 11 compares the modelled stresses without and with the faults. These show a drop in maximum principle stress in the proximity of the fault due to the destressing of the rock as it deforms towards the cave. This shielding of the stress drop in the upper West wall acts in turn to reduce the extent of extensional strains observed behind (i.e. west of) the Mica fault. The effect of the faults on the vertical stresses at depth is further demonstrated in Figure 12. The vertical stresses plotted in this view clearly shows that the Mica fault, and other faults, interferes with the disturbed stress field created by caving. This example also illustrates the concentration of stresses under the northwest wall at the pit bottom due to the presence and orientations of the other faults.

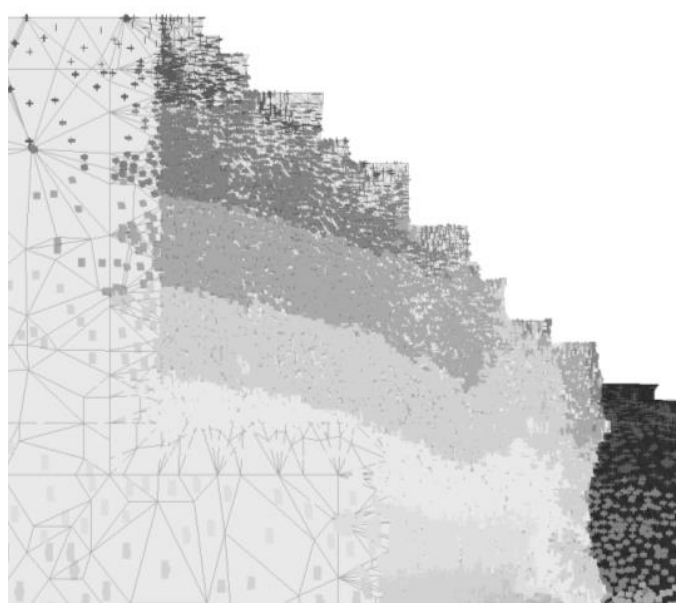

(a) without faults

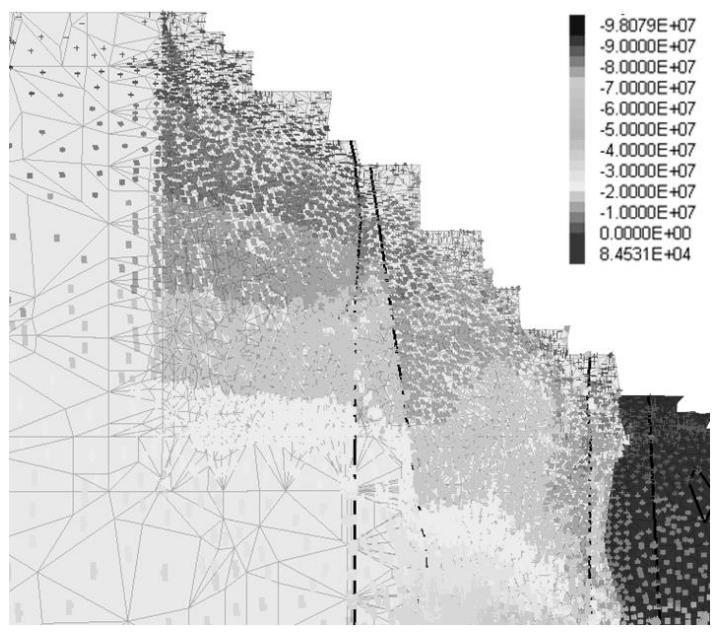

(b) with faults

Figure 11 East-west section of vertical stresses at time of cave breakthrough, for models (a) without faults; (b) with faults. Stresses are in Pa, with compression being negative

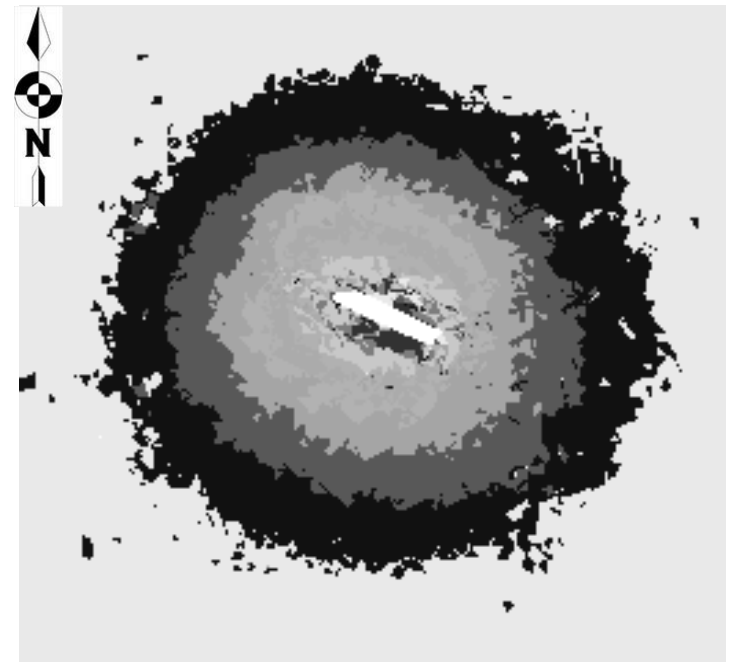

(a) without faults

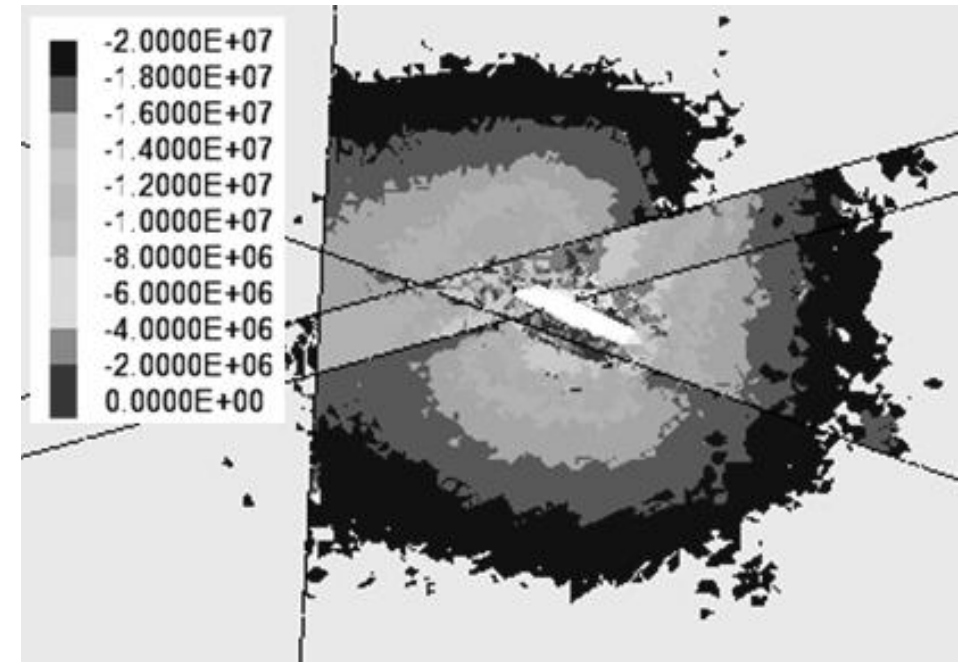

(b) with faults

Figure 12 Vertical stress concentrations observed along horizontal cutting plane taken through model at the level of the pit bottom, for models (a) without faults; (b) with faults. Stresses are in $\mathrm{Pa}$, with compression being negative

The presence of the caved material below overlying slopes has been shown to affect the stresses and strains that develop within a rock mass represented as an equivalent continuum (Sainsbury et al., 2003). The 3D discontinuous effect of faults on the caving induced strains modelled for Palabora is further examined in Figure 13. 

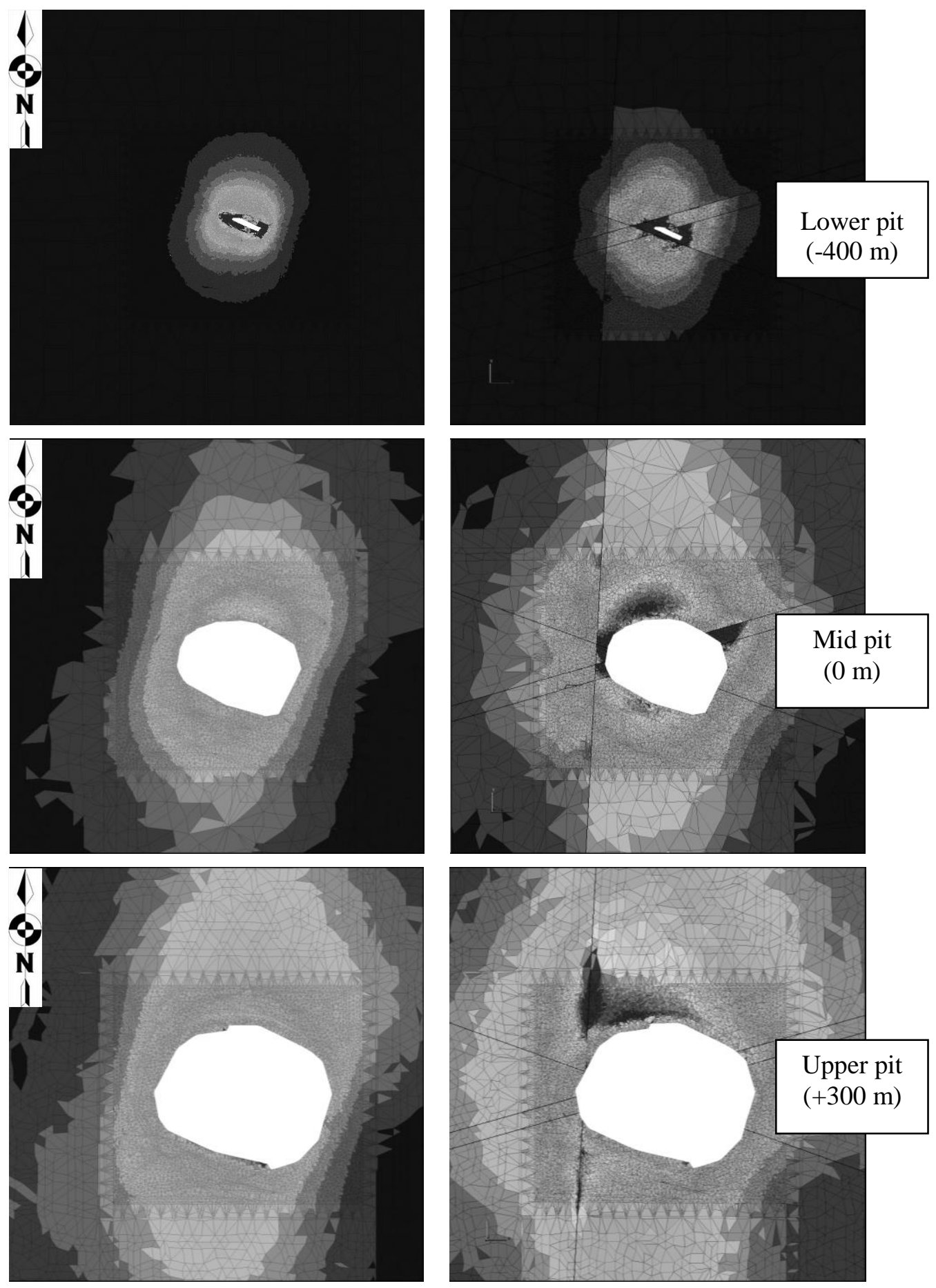

Figure 13 Maximum shear strain distributions within rock mass across horizontal slices at lower, mid, and upper pit levels. Strain magnitudes are increased with the inclusion of fault structures

Shear strain is presented on a series of horizontal planes cut through the 3DEC models with and without faults at: pit bottom (-400 masl), mid slope height (0 masl), and pit crest (300 masl). At the base of the pit, near the top of the cave, the effect of the faults on the shear strain pattern is minimal as the pattern observed is roughly consistent between both sets of models (i.e. without and with faults). Extension of shear strain is observed to the east along the Tree and Central faults as well as a reduction in strain behind the Mica fault to the west. Overall, the magnitude of shear strain in the model with the faults is similar to the model without faults. Closer to the surface, at approximately the mid-height of the pit, the pattern of shear strain is increasingly affected by the interaction between the cave and pit. The presence of the faults allows for more 
strain to occur in the rock mass and changes the distribution of shear strain in the model to create a higher concentration of shear strain behind the northwest wall in the area of eventual pit wall failure. At the level of the pit crest, the effect on the strain concentration near the Mica fault and in the northwest pit rim has become more defined; the presence of the faults has a concentrating effect on the shear strain and rock deformation caused by the stresses responding to cave propagation.

\section{Conclusions}

The example drawn from the Palabora Mine in South Africa shows that by employing a 3D discontinuum approach, using the distinct element program 3DEC, the complex interactions between a propagating block cave, an overlying open pit, and large scale faults transecting the pit can be modelled with respect to the caving induced subsidence pattern generated. Although preliminary, model results in which the major fault zones identified in the pit are included, compared to those in which they are not, show a better fit to the geodetic monitoring data and pit slope displacements recorded from the start of caving through to cave breakthrough and subsequent failure of the northwest wall.

In general, the 3DEC models where faults are included reproduce discontinuous subsidence, with the continuity of the displacements being broken by the faults. More specifically, the interaction between the open pit, cave and fault structures is observed to concentrate and dampen both extensional and shear strains along the Mica fault and West wall. These results closely support several conclusions drawn from the detailed review and analysis of geodetic monitoring data.

\section{Acknowledgements}

The authors would like to thank Dawid Pretorius and the Palabora Mining Company, together with Allan Moss, Andre van As, Alex Vyazmensky and Rio Tinto Technical Services for providing access to the data used in this paper, and Doug Stead at Simon Fraser University for his collaboration on the Canadian Caving and Subsidence project. This work was funded through a Collaborative Research and Development grant from the Natural Sciences and Engineering Research Council of Canada (NSERC) in partnership with Rio Tinto. The authors would also like to thank Reza Taghavi and Dave Christianson of Itasca Consulting Group (Minneapolis) for their help with the Kubrix and 3DEC software programs.

\section{References}

Arndt, S., Beck, D., Reusch, F., Thin, I., Stone, C., Heap, M. and Tyler, D. (2007) Deep and high stress mining Deformation and seismicity, 2007 ABAQUS Users Conference, www.beckarndt.com.au.

Beck, D., Reusch, F., Arndt, S., Thin, I., Stone, C., Heap, M. and Tyler, D. (2006) Numerical modelling of seismogenic development during cave initiation, propagation and breakthrough, in Proceedings Deep and High Stress Mining 2006, Hassani (ed), Balkema, Rotterdam, pp. 405-414.

Board, M., Seldon, S., Brummer, R. and Pakalnis, R. (2000) Analysis of the failure of a large hangingwall wedge: Kidd Mine Division, Falconbridge, Ltd, CIM Bulletin, Vol. 93(1043), pp. 89-97.

Brummer, R., Li, H. and Moss, A. (2006) The transition from open pit to underground mining: An unusual slope failure mechanism at Palabora, Stability of Rock Slopes in Open Pit Mining and Civil Engineering Situations, Johannesburg: SAIMM, Symposium Series S44, pp. 411-420.

Glazer, S. (2003) Seismology: A tool for cave monitoring, Rio Tinto internal presentation.

Hebblewhite, B.K. (2003) Northparkes findings - The implications for geotechnical professionals in the mining industry, 1st Australasian Ground Control in Mining Conference, Sydney, UNSW Press, pp. 3-10.

Itasca Consulting Group Inc. (2003) 3DEC (3Dimensional Distinct Element Code), Version 3.0, Minneapolis: Minnesota.

Moss, A., Diachenko, and Townsend, P. (2006) Interaction between the block cave and the pit slopes at Palabora Mine, Stability of Rock Slopes in Open Pit Mining and Civil Engineering Situations, Johannesburg, SAIMM, Symposium Series S44, pp. 399-410.

Piteau Associates Engineering Ltd (2005) Assessment of Pit Wall Stability and Slope Displacement as a Result of Interaction Between the Open Pit and Underground Mine, internal report.

Piteau Associates Engineering Ltd (2000) Numerical Modelling of The Effects of Open pit deepening and Block Cave Mining on The Stability of the East and North walls, internal report.

Sainsbury, D.P., Pierce, M.E. and Lorig, L.J. (2003) Two- and Three-Dimensional Numerical Analysis of the Interaction Between Open-Pit Slope Stability and Remnant Underground Voids, Harnessing Technology by 
Managing Data and Information, in Proceedings 5th Large Open Pit Conference, Kalgoorlie, Western Australia, C. Workman-Davies and E. Chanda (eds), Carlton, AUSIMM, pp. 251-257.

Sainsbury, D., Pierce, M. and Mas Ivars, D. (2008) Analysis of Caving Behavior using a Synthetic Rock Mass Ubiquitous Joint Rock Mass Modelling Technique, in Proceedings First International FLAC/DEM Symposium on Numerical Modelling, Itasca, Minneapolis, USA.

Sainsbury, D., Pothitos, F., Finn, D. and Silva, R. (2007) Three-Dimensional Discontinuum Analysis of Structurally Controlled Failure Mechanisms at the Cadia Hill Open Pit, in Proceedings International Symposium on Rock Slope Stability in Open Pit Mining and Civil Engineering, Slope07, Yves Potvin (ed), 12-14 September 2007, Perth, Western Australia, Australian Centre for Geomechanics, Perth, Australia, pp. 307-320.

Severin, J., Eberhardt, E. and Stewart, A. (2009) Importance of understanding 3D kinematic controls in the review of displacement monitoring of deep open pits above underground mass mining operations, Rock Engineering in Difficult Conditions, in Proceedings 3rd Canada-US Rock Mechanics Symposium, Toronto, Canada, May 2009.

Stacey, T.R. and Swart, A.H. (2001) Practical rock engineering practice for practice for shallow and opencast mines, SIMRAC, The safety of mines research advisory committee, p. 66.

Vyazmensky, A., Elmo, D. and Stead, D. (2009) Role of rock mass fabric and faulting in the development of block caving induced surface subsidence, Rock Mechanics and Rock Engineering, DOI 10.1007/s00603-009-0069-6, Vol. 1, pp. 467-475. 